\title{
Consultation on the draft regional framework for strengthening the public health response to substance use and substance use disorders in the Eastern Mediterranean Region
}

Citation: Consultation on the draft regional framework for strengthening the public health response to substance use and substance use disorders in the Eastern Mediterranean Region. East Mediterr Health J. 2018;24(11):1112-11123 https://doi.org/10.26719/2018.24.11.1112

Copyright $@$ World Health Organization (WHO) 2018. Some rights reserved. This work is available under the CC BY-NC-SA 3.o IGO license (https:// creativecommons.org/licenses/by-nc-sa/3.o/igo).

\section{Introduction}

The global burden of disease attributable to alcohol and drug use combined is estimated to be higher than the burden attributable to any other risk factor, and in the Eastern Mediterranean Region this burden is largely attributable to drug use (1). According to the World Drug Report 2018, in 2016 an estimated 275 million people (5.6\% of the global adult population) used drugs at least once in the previous year, mainly a substance belonging to the cannabinoid, opioid, cocaine or amphetamine type stimulant (ATS) groups (1). Among these, 30.5 million were problem drug users and suffered from drug use disorders, including drug dependence (1).

In order to address this, an intercountry consultation to review and finalize the draft regional framework for action for strengthening the public health response to substance use and substance use disorders in the Eastern Mediterranean Region was held by the World Health Organization (WHO) in Abu Dhabi, United Arab Emirates, from 11 to 13 September 2018 (2). The consultation brought together focal points on substance use from countries of the Region, civil society organizations, the Joint United Nations Programme on HIV/AIDS (UNAIDS), the United Nations Office on Drugs and Crime (UNODC), and international and regional experts who, in preparation for the meeting, had been engaged in the development of the draft regional framework. The objectives of the meeting were to:

- review and finalize the draft regional framework for action for strengthening the public health response to substance use and substance use disorders; and

- establish a platform for effective regional collaboration to strengthen the public health response to substance use problems in the Region and contribute to the global dialogue on substance use policy, within the public health context.

\section{Summary of discussions}

Over the three days of the meeting, the participants reviewed the currently available capacities and resources for the prevention and treatment of substance use disorders in countries, the evidence underpinning the draft regional framework, as well as the priority areas, proposed strategic interventions and indicators of the draft regional framework, which led to the revision of the framework.

The plenary sessions were focused on introducing the main domains of the proposed regional framework, followed by group work to review the strategic interventions and indicators to monitor progress in their implementation. The group work and subsequent discussions also provided opportunities to review the experiences of countries of our Region and other regions.

Participants identified several overarching challenges that hinder the adoption of a public health approach to substance use disorders. Civil unrest and instability in many countries of the Region affects the capacity of governments to exert their authority in parts of their territory, coupled with an increasing diversion of resources from the social sector towards security.

National policies and legislation are skewed towards supply reduction, with little emphasis on a public health response, resulting in resource constraints. As a result, substance use treatment services have limited reach and capacity to provide an acceptable quality of service. There is also a lack of a control system that both ensures an adequate availability of controlled substances for the management of substance use disorders, and simultaneously prevents an increasing misuse of psychotropic medicines.

There is limited engagement of the health sector in the current debates around the issues of substance use, and a relative lack of engagement across sectors, especially between the public sector and civil society. There is also a paucity of research and research capacity in countries of the Region to inform policies and strategies. Weak monitoring and surveillance systems are unable to provide valid, reliable, comparable and timely information to inform current policies regarding interdiction, prevention and treatment. Participants called for the development of balanced and integrated substance use policies incorporating public health

\footnotetext{
This report is extracted from the Summary report on the Intercountry consultation to review and finalize the draft regional framework for strengthening the public health response to substance use and substance use disorders in the Eastern Mediterranean Region, Abu Dhabi, United Arab Emirates, 11-13 September 2018 (http://applications.emro.who.int/docs/IC_Meet_Rep_2018_EN_20767.pdf?ua=1).
} 
perspectives, and supported by legislative and regulatory provisions. These are important enablers for a robust public health response to the problem of substance use in the countries of the Region.

The discussion focused on the development or updating of strategies, policies and regulatory frameworks, including adapting and implementing the draft regional framework. This will underpin the development of integrated and balanced care service models, within and between sectors, and should include the engagement of all relevant stakeholders, across the domains of prevention, early recognition, management, rehabilitation and harm reduction. To support this, robust health information systems are needed that collect and report data using standard internationally comparable indicators.

The participants also identified the need to adopt/ adapt UNODC/WHO treatment and prevention standards, and the need to integrate substance use care in existing health systems through inclusion of substance use interventions in the universal health coverage benefit packages currently being developed in countries across the Region. The need to strengthen the component of substance use and its disorders in pre-service teaching and training for health and social sector care providers was also highlighted, as was the need to quantitatively and qualitatively improve specialist training programmes.

A particular area of concern was the limited availability of the essential medicines needed for the management of substance use disorders, such as methadone and buprenorphine/naltrexone, and the need for a system for the adequate monitoring and surveillance of the prescription of psychoactive drugs.

The participants strongly supported the embedding of age- and setting-specific substance use prevention in health promotion and prevention policies and programmes across life course. The need to strengthen the capacities of institutions in countries to undertake operational research to guide policy and service development was also pointed out.

\section{Recommendations}

\section{For Member States}

- Ensuring that national focal points on substance use engage with their counterparts in relevant ministries, as well as with their diplomatic missions in Geneva and New York, so that a public health perspective is reflected in the ongoing dialogue around substance use and substance use disorders.

\section{For WHO}

- Finalizing the draft regional framework for action for strengthening the public health response to substance use and substance use disorders over the next four weeks through virtual consultation with national counterparts, civil society and United Nations (UN) sister organizations.

- Ensuring buy-in at the highest possible level of national policy/decision-making for the regional framework by presenting it to the Sixty-sixth Session of the WHO Regional Committee for the Eastern Mediterranean in October 2019.

- In collaboration with UN agencies, providing continued advocacy with organizations such as the League of Arab States, Gulf Cooperation Council and the Group of Five (G5).

- In collaboration with UN agencies, enhancing the capacities of substance use units/directorates to engage in policy dialogue and support implementation of the regional framework.

- In collaboration with UN agencies, facilitating the active engagement and participation of public health representatives in the ongoing national and international dialogue, including briefing health attachés from countries in the permanent missions in Geneva and New York.

- Exploring avenues for setting up and maintaining a regional network for strengthening the public health response to substance use and substance use disorders.

\section{References}

1. United Nations Office on Drugs and Crime (UNODC). World Drug Report 2018. New York: UNODC; 2018 (https://www.unodc. org/wdr2018/).

2. World Health Organization Regional Office for the Eastern Mediterranean (WHO/EMRO). Intercountry consultation to review and finalize the draft regional framework for strengthening the public health response to substance use and substance use disorders in the Eastern Mediterranean Region. Cairo: WHO/EMRO; 2018 (http://applications.emro.who.int/docs/IC_Meet_ Rep_2018_EN_20767.pdf?ua=1). 